\title{
Tissue-specific Nutrient Metabolism in the Liver and Muscle of Juvenile Blunt Snout Bream (Megalobrama Amblycephala) in Response to Dietary Methionine Levels
}

$\mathrm{Ke} \mathrm{Ji}$

Wuxi Fisheries College

Hualiang Liang

Chinese Academy of Fishery Sciences Freshwater Fisheries Research Center

Mingchun Ren ( $\nabla$ renmc@ffrc.cn )

Chinese Academy of Fishery Sciences Freshwater Fisheries Research Center

\section{Xianping Ge}

Chinese Academy of Fishery Sciences Freshwater Fisheries Research Center

\section{Lu Zhang}

Tongwei Co., Ltd.

\section{Liangkun Pan}

Freshwater Aquaculture Research Center

Heng Yu

Wuxi Fisheries College

\section{Research}

Keywords: Blunt snout bream (Megalobrama amblycephala), Methionine, Nutrient metabolism, Tissuespecific

Posted Date: January 28th, 2021

DOl: https://doi.org/10.21203/rs.3.rs-152597/v1

License: (c) (i) This work is licensed under a Creative Commons Attribution 4.0 International License. Read Full License 


\section{Abstract}

\section{Background}

Methionine is an essential amino acid, that affects the metabolism of protein, lipid and glucose. However, the metabolic polytrophic response in the liver and muscle of juvenile Megalobrama amblycephala to dietary methionine levels is unclear.

\section{Results}

The $0.84 \%$ methionine diet significantly improved the growth performance compared with the $0.40 \%$ diet. Dietary methionine levels had no marked effects on plasma parameters or whole body composition of juveniles. The protein levels of phospho-phosphatidylinositol 3-kinase, protein kinase B, phosphoeukaryotic initiation factor 4E binding protein-1 (p-4E-BP1), 4E-BP1 and ribosomal protein S6 kinase 1, in the liver of fish fed the $0.84 \%$ diet were higher than those in fish fed the $0.40 \%$ diet. While in muscle, these proteins showed the opposite trend. The mRNA levels of the muscular lipid synthesis associated genes: sterol regulatory element-binding protein 1 (SREBP1), fatty acid synthetase (FAS) and acetyl-CoA carboxylase (ACC), were significantly upregulated by the $1.28 \%$ methionine diet; while hepatic SREBP1, FAS and ACC mRNA expression levels were increased by $0.40 \%$ methionine. In addition, $1.28 \%$ dietary methionine significantly induced fatty acid $\beta$-oxidation and lipolysis of the liver and muscle via increased carnitine palmitoyl transferase 1, peroxisome proliferator activated receptor alpha, lipoprotein lipase and lipase expression levels. Compared with $0.40 \%$ dietary methionine, $1.28 \%$ methionine enhanced the mRNA levels of the hepatic gluconeogenesis related genes phosphoenolpyruvate carboxykinase (PEPCK) and glucose-6-phosphatase, and the muscular glycolysis related genes phosphofructokinase (PFK) and pyruvate kinase (PK). The mRNA expression levels of hepatic PFK, PK and glucokinase were markedly upregulated by the $0.84 \%$ methionine diet compared with the $1.28 \%$ diet. In addition, muscular PEPCK and glycogen synthase, and hepatic glucose transporters 2 mRNA levels were induced by $1.28 \%$ methionine.

\section{Conclusion}

The study showed that optimal methionine levels could enhance the growth of juvenile Megalobrama amblycephala, and the nutrient metabolism response to dietary methionine in the liver and muscle was tissue-specific.

\section{Background}

For animals, methionine (Met) is an important essential amino acid, that must be provided by feed [1, 2]. An increasing number of studies have reported that Met is conducive to the growth and health of animals including mammals and fish [3-7]. Moreover, Met has been suggested to regulate the nutrient metabolism involving protein, lipid and glucose in animals and human [8-12]. Similarly, in fish, dietary Met affected glucose and lipid metabolism was reported. The primary muscle cells of turbot 
(Scophthalmus maximus L.) under Met deprivation showed inhibited expression of key target of rapamycin (TOR) pathway elements, and genes related to glycolysis and fatty acid synthesis, while induced fatty acid $\beta$-oxidation [13]. Similarly, in cobia (Rachycentron canadum), Met deficiency suppressed hepatic lipogenesis related gene (sterol regulatory element-binding protein (SREBP) and fatty acid synthetase (FAS)) expression and upregulated fatty acid oxidation-related gene (carnitine palmitoyl transferase 1 (CPT1), peroxisome proliferator activated receptor alpha (PPARa), and lipoprotein lipase (LPL)) expression, while increased phosphoenolpyruvate carboxykinase (PEPCK) mRNA levels [14, 15]. Moreover, the nutrient metabolism response to dietary Met showed species-specific and tissue-specific responses. Rainbow trout (Oncorhynchus mykiss) fed Met-deficient diets showed a positive relationship with hepatic FAS expression, while negative with CPT1 and fructose-1,6-biphosphatase (FBP) mRNA levels [16]. Met deficiency and excess could induce hepatic lipid accumulation in yellow catfish (pelteobagrus fulvidraco) [17]. Lipid content in the liver was increased, while lipid content in the muscle was decreased in rainbow trout fed Met restricted diets for 8 weeks [18]. Therefore, the response of aquaculture fish to dietary Met is complex. Data about the effects of dietary Met on nutrient metabolism in fish are scarce, and these effects need to be further investigated.

The liver and muscle are important nutrient metabolism organs in animals. In fish, the liver and muscle are both main sites of protein synthesis, lipid synthesis and excess carbohydrate storage $[19,20]$. In fish, studies have suggested that nutrient sensing (TOR or amino acid response (AAR) signaling) and metabolic responses (including protein, lipid and glucose metabolism) were influenced by nutrients and changes in the composition of diets [21-24]. Some studies have paid particular attention to the change in nutrient metabolism in different organs or tissues in fish. Chen et al. [25] reported that the lipid metabolism of yellow catfish in response to waterborne $\mathrm{Cd}$ exposure is tissue-specific; hepatic lipid accumulation was induced, while both lipogenesis and lipolysis were downregulated in muscle. Compared with Met-sufficient feed, Met-restricted feed significantly increased the liver fat content and decreased the muscle fat content of rainbow trout [18]. Rainbow trout refeeding high protein-low carbohydrate diets showed significantly suppressed hepatic glucokinase (GK) and glucose-6phosphatase 1 (G6pase1) mRNA levels, increased FAS and SREBP1 mRNA expression; while in muscle, refeeding high protein-low carbohydrate diets induced glucose transporters 4 (GLUT4) expression, and these diets had no significant effects on acetyl-CoA carboxylase (ACC) mRNA levels [26]. These results indicated that the metabolic response of fish to dietary nutrients is tissue-specific. However, only a few papers have studied metabolism in the peripheral tissues of fish involving muscle and liver responses to dietary nutrients, and the potential regulatory mechanism needs further investigation.

Blunt snout bream, Megalobrama amblycephala, is the main freshwater aquaculture species in China. Our previous studies have confirmed the dietary Met requirement and studied the immunity and antioxidant capacity of dietary methionine on blunt snout bream [27, 28]. However, the information related to nutrient metabolism changes response to dietary Met in this species is still unknown. Based on the metabolic polytrophic response of different fish and tissues to dietary Met levels, the current study was designed to investigated the effects of dietary Met levels on the nutrient metabolism of Megalobrama amblycephala, and to study the different metabolic responses in the liver and muscle. 


\section{Methods}

\section{Experimental design and diets}

In view of the dietary Met requirement of juvenile blunt snout bream determined by Liao et al. [27], three isonitrogenous and isoenergetic feeds with the followed graded dietary Met levels were formulated:

$0.40 \%$ (control), $0.84 \%$ (optimal) and $1.28 \%$ (high). The composition of the basal feed was shown in Table 1, and glycine was used to balance Met supplementation, as mentioned in our previous study [28]. The amino acid contents of the experimental diets are the same as those shown in the previous study by $\mathrm{Ji}$ et al. [28]. As described in our previous study [27], the pellet diets were processed by F-26 (II) (South China University of Technology, China), air-dried, and finally stored in a refrigerator at $-20^{\circ} \mathrm{C}$ until feeding. 
Table 1

Ingredient composition of basal diets (\% dry basis)

\section{Ingredients (\%)}

Fish meal ${ }^{1}$

Rapeseed meal ${ }^{1}$

12

Soybean meal ${ }^{1}$

30

Wheat meal ${ }^{1}$

28

Rice meal ${ }^{1}$

12.78

Soybean oil

1.5

Soybean phospholipid

1

Amino acid premix ${ }^{2}$

5.72

Vitamin C

Vitamin and mineral premix ${ }^{3}$

Monocalcium phosphate

3

Choline chloride

0.1

Ethoxy quinoline

0.01

Glycine

0.84 *

L-methionine

0 *

Bentonite

2

Note: the basal diet in this experiment was referred to our previous study (Ji et al., 2020).

${ }^{1}$ The composition of fish meal, rapeseed meal, soybean meal, wheat meal, and rice meal as showed in our previous study (Ji et al., 2020). Protein sources obtained from Wuxi Tongwei feedstuffs Co., Ltd, Wuxi, China.

${ }^{2}$ The details of amino acid premix as showed in our previous study (Ji et al., 2020). Amino acids obtained from Feeer Co., LTD (Shanghai, China).

${ }^{3}$ The detail of vitamin and mineral premix as showed in our previous study (Ji et al., 2020).

\section{Experimental fish and feeding}

As mentioned in our previous study [28], the experimental fish were obtained from the breeding farm of Freshwater Fisheries Research Center (FFRC) of Chinese Academy of Fishery Sciences (Wuxi, Jiangsu, China). After a 15-day acclimation period, the juvenile fish consistent with health and specification (initial 
weight $4.37 \pm 0.01 \mathrm{~g})$ were randomly selected into nine cages, and one parallel cage $(1 \mathrm{~m} \times 1 \mathrm{~m} \times 1 \mathrm{~m})$ with 20 fish. The experiment lasted for 75 days, and the feeding times were 7:30, 12:00 and 4:30. The water quality was tested weekly, the water temperature was maintained at 28 to $31^{\circ} \mathrm{C}, \mathrm{pH}$ was maintained from 7.0 to 7.8 , ammonia nitrogen was not higher than $0.05 \mathrm{mg} / \mathrm{L}$ and dissolved oxygen was higher than 6.0 $\mathrm{mg} / \mathrm{L}$.

\section{Sampling}

$24 \mathrm{~h}$ after the fish were fasted, the total weight and amount of fish in one parallel cage were counted to calculate the relative growth indices at the end of the experiment. Five fish from one parallel cage were anesthetized by using MS-222 (100 mg/L), and then to collect blood, liver and muscle samples. Plasma was obtained by the centrifugation of blood samples $\left(3500 \times \mathrm{g}, 10 \mathrm{~min}, 4^{\circ} \mathrm{C}\right)$. An additional two fish from each cage were collected to test whole body composition. The samples were stored at $-80^{\circ} \mathrm{C}$ until analyzed.

\section{Analyses of composition and amino acids}

The content of moisture, crude protein and lipid, and ash of feeds, whole body and ingredients were analyzed according to the methods described in AOAC [29]. The concentrations of amino acid in feeds and ingredients were analyzed by using an amino acid analyzer (SYKAM S-433D, Sykam GmbH, Munich, Germany).

\section{Analyses of plasma parameters}

Plasma glucose (GLU), total cholesterol (TC), and total triglyceride (TG) were tested by using Mindray BS400 automatic biochemical analyzer (Mindray Medical International Ltd., Shenzhen, China), assay kits purchased from Shanghai Zhicheng Biological Technology Co. Ltd (Shanghai, China).

\section{Quantitative real-time PCR (qRT-PCR)}

Total RNA from the liver and muscle was extracted by RNAiso Plus (Cat\# 9109, Takara, Baobio Engineering (Dalian) Co., Ltd, Dalian, China). The quality and quantity of RNA were tested by a spectrophotometer (Thermo Fisher Multiskan GO, Shanghai, China). Finally, qRT-PCR was performed according to the instructions of One Step TB Green ${ }^{\circledR}$ PrimeScript ${ }^{\circledR}$ Plus RT-PCR Kit (Cat\# RR096A, Takara, Baobio Engineering (Dalian) Co., Ltd, Dalian, China) on a CFX96 Touch Real-Time PCR Detection System (BIO-RAD, California, USA). Specific primers of target genes (Table 2) were designed according to the partial cDNA sequences showed in Gao et al. [30]. The assay used $\beta$-actin as the reference gene, and the target gene expression levels were analyzed using the $2^{-\Delta \Delta c t}$ model. 
Table 2

Primer sequence for qRT-PCR

\begin{tabular}{|c|c|c|}
\hline \multirow[t]{2}{*}{ Target gene } & \multicolumn{2}{|l|}{ Primer sequence } \\
\hline & Forward (5'-3') & Reverse (3'-5') \\
\hline $\mathrm{TOR}^{1}$ & TTTACACGAGCAAGTCTACGGA & СTTCATCTTGGCTCAGCTCTCT \\
\hline $4 \mathrm{E}-\mathrm{BP} 1^{2}$ & GCTGGCTGAGTTTGTGGTTG & CGAGTCGTGCTAAAAAGGGTC \\
\hline $\mathrm{S} 6 \mathrm{~K} 1^{3}$ & GGTGCATGTCACCTTATGGG & AGCTGGCAGCACTTCTAGTC \\
\hline $\mathrm{GK}^{4}$ & GCTTCCACTGGGATTCACCT & CGACGTTATTGCCTTCAGCG \\
\hline $\mathrm{PK}^{5}$ & CGAGATTGAGAACGGAGGCA & GTCCTTCTCAGACACTGCGG \\
\hline $\mathrm{PFK}^{6}$ & TAGGATCAAGCAATCCGCCG & CCTGCCATGGTTGCCAGATA \\
\hline PEPCK $^{7}$ & TCGCCTGGATGAAGTTCGAC & GTCTTGGTGGAGGTTCCTGG \\
\hline G6Pase $^{8}$ & TTCAGTGTCACGCTGTTCCT & TCTGGACTGACGCACCATTT \\
\hline $\mathrm{FBP}^{9}$ & CGGCAGCCCATTATCATTGC & GCGTACACTGGACTCTCCAC \\
\hline $\mathrm{GS}^{10}$ & TTACACGGTCATTGCGTCCA & GACACAGCTCAGTCGGTGAA \\
\hline $\mathrm{G} \mathrm{PD}^{11}$ & TGGAGAAACCTTTTGGCCGT & CTGGGTACCAAACGGCTCTT \\
\hline GLUT2 $2^{12}$ & CGGTGAAACCGAACAGGAGT & TTCTTTGAGATCGGGCCTGG \\
\hline GLUT4 $4^{13}$ & CCATTGCTGAGCTCTTTCGC & GCGTACACTGGACTCTCCAC \\
\hline $\mathrm{ACC}^{14}$ & TAGCAGTGAGCATTGGCACA & CATCGCTGGCGTATGAGGAT \\
\hline FAS $^{15}$ & GTTTGCCAACCGCTTGTCTT & GGCCATGGCGAATAGCATTG \\
\hline SREBP $1^{16}$ & ACAACAGTAGCGACACCCTG & AGGAGCGGTAGCGTTTTTCA \\
\hline $\mathrm{CPT} 1^{17}$ & CAAGCTCTGAGGGCCAAAGG & TGTACCATCGAGGCCGTTTC \\
\hline PPARa $^{18}$ & CGTTGACGTCCTTCTCTGCT & ATGTCCCACAACGCTATCCG \\
\hline $\mathrm{LPL}^{19}$ & GCCACGAGTGTTGGTGTGAA & TGGCCCTAGCTTTGAGTACG \\
\hline Lipase & GTTTCTGGATTTGGGTCG & TCTGATGGGATCTGGCAC \\
\hline$\beta$-actin & TCGTCCACCGCAAATGCTTCTA & CCGTCACCTTCACCGTTCCAGT \\
\hline
\end{tabular}


${ }^{1} \mathrm{TOR}$, Target of rapamycin; ${ }^{2} 4 \mathrm{E}-\mathrm{BP} 1$, Eukaryotic initiation factor $4 \mathrm{E}$ binding protein- $1 ;{ }^{3} \mathrm{~S} 6 \mathrm{~K} 1$, Ribosomal protein 66 kinase $1 ;{ }^{4} \mathrm{GK}$, Glucokinas; ${ }^{5} \mathrm{PK}$, Pyruvate kinase; ${ }^{6} \mathrm{PFK}$, Phosphofructokinase; ${ }^{7} \mathrm{PEPCK}$, Phosphoenolpyruvate carboxykinase; ${ }^{8} \mathrm{G} 6 \mathrm{Pase}$, Glucose-6-phosphatase; ${ }^{9} \mathrm{FBP}$, Fructose-1,6biphosphatase; ${ }^{10} \mathrm{GS}$, Glycogen synthase; ${ }^{11} \mathrm{G} 6 \mathrm{PD}$, Glucose-6-phosphate dehydrogenase; ${ }^{12} \mathrm{GLUT} 2$, Glucose transporters $2 ;{ }^{13} \mathrm{GLUT4}$, Glucose transporters $4 ;{ }^{14} \mathrm{ACC}$, Acetyl-CoA carboxylase; ${ }^{15} \mathrm{FAS}$, Fatty acid synthetase; ${ }^{16}$ SREBP1, Sterol regulatory element-binding protein $1 ;{ }^{17} \mathrm{CPT} 1$, Carnitine palmitoyl transferase $1 ;{ }^{18}$ PPARa, Peroxisome proliferator activated receptor alpha; ${ }^{19} \mathrm{LPL}$, Lipoprotein lipase.

\section{Western blot analysis}

$50 \mathrm{mg}$ liver and muscle samples were rinsed twice with ice-cold PBS, the PBS was removed by centrifugation, and then the tissues were put into ice-cold RIPA buffer (50 mM Tris, pH 8.0; $150 \mathrm{mM} \mathrm{NaCl}$; $1 \%$ TritonX-100; $0.1 \%$ SDS; $1 \%$ sodium deoxycholate; $1 \mathrm{mM}$ EDTA) with $5 \mathrm{mM} \mathrm{NaF}, 2 \mathrm{mM} \mathrm{Na}{ }_{4} \mathrm{P}_{2} \mathrm{O}_{7}, 2 \mathrm{mM}$

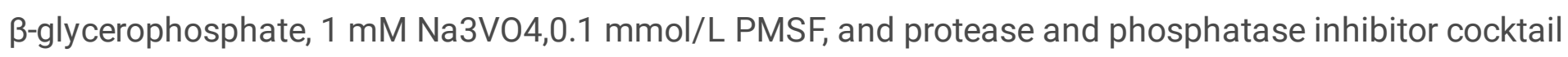
(RFT194, Biolab). The supernatant was collected after centrifugation at $12,000 \times \mathrm{g}$ for $10 \mathrm{~min}$ at $4^{\circ} \mathrm{C}$. The protein contents were tested by the BCA method (BB-3401, BestBio). Quantified samples were added to prefabricated SDS-PAGE gels for electrophoresis and then transferred to NC membrane (66485, Bio Trace). The blot was blocked with $5 \%$ nonfat dry milk in TBST for $2 \mathrm{~h}$ at room temperature. After overnight incubation of the membrane and primary antibodies, the membrane was incubated for $1 \mathrm{~h}$ with appropriate secondary antibodies. A Beyo ECL Star kit (Beyotime biotechnology) was used to develop the signal. The bends were scanned and quantified using a chemiluminescence imaging system (Clinx, Shanghai, China). Antibodies against the following proteins were used: phospho-phosphatidylinositol 3kinase (p-PI3K, Tyr458/Tyr199) (Cat\# 4228), phospho-eukaryotic initiation factor 4E binding protein-1 ( $\mathrm{p}$ 4E-BP1, Thr37/46) (Cat\# 9459), and 4E-BP1 (Cat\# 9452) were purchased from Cell Signaling Technology Inc. PI3K (Cat\# 20584-1-AP), ribosomal protein S6 kinase 1 (S6K1, Cat\# 1485-1-AP) and protein kinase B (AKT, Cat\# 10176-2-AP) were purchased from Proteintech Group, Inc. And $\beta$-actin (Cat\# AY0573) was purchased from Abways Technology. The densities of the protein bands were normalized to that of $\beta$ tubulin, which served as an internal control.

\section{Statistical analysis}

Data were analyzed by one-way analysis of variance (ANOVA) and Tukey's multiple comparisons with SPSS 16.0 software. The results are presented as the means with SEM and $P<0.05$ indicates a statistical significance.

\section{Results}

\section{The growth performance}


As shown in Table 3, final body weight (FBW), weight gain rate (WGR) and specific growth rate (SGR) in fish fed Met-supplemented diets $(0.84 \%$ and $1.28 \%$ dietary Met) were significantly increased compared with those in fish fed $0.40 \%$ diet $(P<0.05)$. FBW, SGR and WGR were significantly lower in the $0.40 \%$ Met diet group than the $0.84 \%$ Met diet $(P<0.05)$. While the value of feed conversion ratio (FCR) showed the opposite trend.

Table 3

The effects of dietary methionine levels on the growth performance of juvenile blunt snout bream (Megalobrama amblycephala) (means \pm SEM) ${ }^{1}$

\begin{tabular}{|c|c|c|c|c|c|}
\hline $\begin{array}{l}\text { Dietary Met levels } \\
\text { (\%) }\end{array}$ & $\mathrm{IBW}^{2}(\mathrm{~g})$ & $\mathrm{FBW}^{3}(\mathrm{~g})$ & $\mathrm{FCR}^{4}$ & $\begin{array}{l}\text { SGR }^{5} \\
\text { (\%/day) }\end{array}$ & WGR $^{6}(\%)$ \\
\hline 0.40 & $\begin{array}{l}4.38 \pm \\
0.01\end{array}$ & $\begin{array}{l}44.60 \pm \\
0.17^{\mathrm{a}}\end{array}$ & $0.92 \pm 0.02^{b}$ & $3.10 \pm 0.01^{\mathrm{a}}$ & $918.97 \pm 6.33^{a}$ \\
\hline 0.84 & $\begin{array}{l}4.35 \pm \\
0.01\end{array}$ & $\begin{array}{l}51.41 \pm \\
0.25^{c}\end{array}$ & $0.82 \pm 0.01^{\mathrm{a}}$ & $3.29 \pm 0.01^{c}$ & $\begin{array}{l}1081.02 \pm \\
5.85^{c}\end{array}$ \\
\hline 1.28 & $\begin{array}{l}4.37 \pm \\
0.01\end{array}$ & $\begin{array}{l}46.90 \pm \\
0.40^{\mathrm{b}}\end{array}$ & $\begin{array}{l}0.87 \pm \\
0.01^{\mathrm{ab}}\end{array}$ & $3.17 \pm 0.01^{b}$ & $977.55 \pm 9.81^{b}$ \\
\hline
\end{tabular}

${ }^{1}$ All data are mean value of three replicates \pm SEM. Means in the same column with different superscripts are significantly different $(P \otimes 0.05)$.

2IBW: Initial body weight.

${ }^{3}$ FBW: Final body weight.

${ }^{4}$ Feed conversion ratio $(F C R)=$ dry feed fed $(\mathrm{g}) /$ wet weight gain $(\mathrm{g})$.

${ }^{5}$ Specific growth rate $(S G R, \% /$ day $)=100 \times($ In final fish weight - In initial fish weight $) /$ the experimental duration in days.

${ }^{6}$ Weight gain rate (WGR) $(\%)=100 \times($ final weight $(\mathrm{g})$-initial weight $(\mathrm{g})) /$ initial weight $(\mathrm{g})$.

\section{Whole body composition}

As shown in Table 4, there were no marked differences in whole body composition (moisture, crude protein and lipid, ash) contents among the fish fed the three practical diets $(P>0.05)$. 
Table 4

Effects of dietary methionine levels on whole body composition of blunt snout bream (Megalobrama amblycephala) (Means \pm SEM) ${ }^{1}$

\begin{tabular}{|lcccc|}
\hline Dietary Met levels (\%) & Moisture (\%) & Protein (\%) & Lipid (\%) & Ash (\%) \\
\hline 0.40 & $73.05 \pm 0.25$ & $16.30 \pm 0.10$ & $6.56 \pm 0.05$ & $3.49 \pm 0.16$ \\
\hline 0.84 & $73.64 \pm 0.22$ & $16.67 \pm 0.20$ & $6.27 \pm 0.04$ & $3.21 \pm 0.04$ \\
\hline 1.28 & $73.61 \pm 0.05$ & $16.53 \pm 0.11$ & $6.27 \pm 0.11$ & $3.43 \pm 0.03$ \\
\hline $\begin{array}{l}\text { 1All data are mean value of three replicates } \pm \text { SEM. Means in the same column with different } \\
\text { superscripts are significantly different }(P \otimes 0.05) .\end{array}$ \\
\hline
\end{tabular}

\section{The plasma parameters}

As shown in Fig. 1, the dietary Met levels had no significant effects on the levels of plasma GLU, TC, and TG, although GLU contents tended to increase with increasing dietary Met levels $(P>0.05)$.

\section{The protein and gene expression levels of TOR signal pathway in the liver and muscle}

As shown in Fig. 2A and 2B, the protein levels of p-4E-BP1, 4E-BP1, S6K1 and PI3K in the liver of fish fed the $0.84 \%$ Met diet were higher than those in fish fed $0.40 \%$ diet. In muscle, these proteins showed the converse trend (Fig. 2C). The hepatic protein levels of p-PI3K and AKT in $0.40 \%$ Met group were higher than those in $0.84 \%$ group (Fig. 2B). In muscle, the p-PI3K and AKT protein levels in $0.40 \%$ and $0.84 \%$ diets were similar, and lower than those in liver (Fig. 2C).

The mRNA expression levels were shown in Fig. 2D. Compared with $0.84 \%$ dietary Met, $0.40 \%$ Met significantly promoted hepatic TOR mRNA expression levels, while hepatic 4E-BP1 expression levels were significantly upregulated by $1.28 \%$ Met level $(P<0.05)$. The relative expression levels of S6K1 in both the liver and muscle were markedly upregulated by $0.84 \%$ dietary Met compared with $0.40 \%$ methionine level $(P<0.05)$. Dietary Met levels had no significant effects on muscular TOR or 4EBP1 mRNA expressions $(P$ $>0.05)$.

\section{The expression of lipid metabolism related genes in the liver and muscle}

As presented in Fig. 3B, the mRNA levels of muscular SREBP1, FAS, ACC, CPT1, PPARa and LPL were significantly upregulated in fish fed $1.28 \%$ Met diet, compared with $0.40 \%$ or $0.84 \%$ Met diet $(P<0.05)$; while hepatic SREBP1, FAS and ACC mRNA levels were induced by $0.40 \%$ dietary Met level $(P<0.05)$ (Fig. 3A). Hepatic CPT1 and PPARa expression were increased with increasing dietary Met levels $(P<$ 0.05) (Fig. 3A). Dietary Met levels of $0.84 \%$ significantly induced hepatic Lipase mRNA levels compared with $1.28 \%$ Met level $(P<0.05)$ (Fig. 3A). There were no significant differences in the relative expression levels of muscular Lipase and hepatic LPL in fish fed the graded Met level diets $(P>0.05)$. The relative 
expression levels of glucose-6-phosphate dehydrogenase (G6PDH) in both the liver and muscle were not significantly affected by dietary Met levels $(P>0.05)$.

\section{The expression of glucose metabolism related genes in the liver and muscle}

As presented in Fig. 4A and 4B, the mRNA expression levels of hepatic PEPCK and G6Pase, and muscular PEPCK, phosphofructokinase (PFK), pyruvate kinase (PK) and glycogen synthase (GS) were markedly increased by $1.28 \%$ Met diet compared with $0.40 \%$ diet $(P<0.05)$. GK, PFK and PK mRNA levels in the liver were significantly suppressed by $1.28 \%$ diet compared with $0.84 \%$ diets $(P<0.05)$. Glucose transporters 2 (GLUT2) expression in the liver were significantly induced by $1.28 \%$ Met diet compared to $0.84 \%$ diet $(P<$ 0.05); while muscular GLUT4 and FBP, and hepatic GS and FBP expression levels were not markedly affected by dietary Met levels $(P>0.05)$.

\section{Discussion}

Optimal dietary methionine levels improved the growth performance of juvenileMegalobrama amblycephala

Optimal Met levels in diets could improve the growth performance of fish, which has been proven in many fish species, such as: large yellow croaker, Pseudosciaena crocea R [5]; grass carp, Ctenopharyngodon idella [7]; blunt snout bream [27]; Chinese sucker, Myxocyprinus asiaticus [31]; and juvenile cobia [32]. Similarly, in the present study, the data related to growth performance indicated that Met supplementation ( $0.84 \%$ and $1.28 \%$ dietary Met) significantly improved WGR, SGR and FBW of juvenile blunt snout bream compared with the diet without Met supplementation ( $0.40 \%$ methionine diet). This result was consistent with the conclusion in Liao et al. [27] that dietary methionine played important roles in the growth performance of juvenile Megalobrama amblycephala. In our present study, juveniles fed diets containing graded dietary methionine levels showed no significant difference in whole body composition. Similar results were also reported in large yellow croaker and juvenile cobia [5,32]. Meanwhile, the present data showed that whole body protein contents in $0.84 \%$ and $1.28 \%$ groups were slightly higher than that in the $0.40 \%$ group, while the lipid contents were slightly lower. Studies in Chinese sucker, blunt snout bream and Indian major carp (Cirrhinus mrigala) also revealed that optimal dietary methionine levels markedly increased crude protein and decreased crude lipid content in whole body composition [27, 31, 33]. However, Yan et al. [34] reported that whole body protein and lipid contents were significantly increased with increasing dietary methionine up to $1.58 \%$ in juvenile rockfish (Sebastes schlegeli). These results suggested that the whole body composition of different fish species in response to dietary methionine varies and might reflect changes in nutrient metabolism. However, the mechanism of the specificcatabolism response to dietary methionine is unclear, and needs to be further investigated.

$0.40 \%$ dietary methionine impaired hepatic TOR signaling, while improved muscular TOR signaling in juvenileMegalobrama amblycephala 
The present study investigated the response of TOR pathway related protein synthesis to dietary methionine. $0.40 \%$ dietary Met level inhibited TOR signaling, while $0.84 \%$ Met activated TOR signaling in the liver of blunt snout bream; this was evidenced by reduced protein levels of hepatic S6K1 and p-4E$\mathrm{BP} 1$, which are the downstream of TOR that regulate protein synthesis [35], in the $0.40 \%$ diet group. The $0.84 \%$ dietary Met induced hepatic S6K1 and p-4E-BP1 protein levels, indicating that the liver of blunt snout bream is sensitive to Met via TOR pathway, and $0.84 \%$ Met diet could promote hepatic protein synthesis compared with the $0.40 \%$ diet. Prior to this study, Dai et al. [36] reported that trout hepatocytes treated with amino acids $\left(4^{\star} \mathrm{AA}\right)$ combined with insulin significantly activated TOR pathway compared with the control. The present study was also consistent with the finding that TOR pathway key genes in porcine mammary epithelial cells were significantly increased by a mix of D- and L-Met compared with no methionine [37]. However, TOR pathway response to dietary Met in blunt snout bream showed a tissuespecific and dose-dependent response in this study. Increasing protein levels of S6K1, 4E-BP1 and p-4EBP1 in the muscle of blunt snot bream were observed in the $0.40 \%$ Met diet but not in the $0.84 \%$ diet that similar to the liver. Additionally, the trends in the mRNA expression levels of TOR pathway key genes were different from the trends at the protein level. Similar phenomena also were observed in the study by Zeitz et al. [9], which may be due to the temporal and spatial differences between transcription and translation.

\section{$0.40 \%$ dietary methionine increased hepatic lipid accumulation, while suppressed lipogenesis in muscle in juvenileMegalobrama amblycephala}

In the present study, hepatic SREBP1, ACC and FAS mRNA levels were markedly induced by $0.40 \%$ dietary Met compared with $0.84 \%$ or $1.28 \%$ Met level. SREBP1 is an important nuclear transcription factor in lipid synthesis, that controls the synthesis of enzymes involved in ACC and FAS [38, 39]. These results indicated that low Met (0.40\%) may promote liver lipid synthesis via increasing related genes in blunt snout bream. In Atlantic salmon (Salmo salar), methionine deficiency contributes to high FAS activity and triglyceride accumulation in the liver [40]. Met deficiency also induced FAS and SREBP1 expression in rainbow trout [41]. In growing pigs, Met restriction enhanced FAS gene expression and whole lipogenic capacities $[4,8]$. Recent studies reports that PI3K/AKT activates SREBPs, major transcriptional regulators of lipid metabolism $[42,43]$. AKT activation was reported to be the necessary and sufficient factor for the increase of SREBP1c and lipid accumulation in liver [44, 45]. Yecies et al. [46] found AKT induces hepatic SREBP1c and lipogenesis via parallel mTORC1-dependent and mTORC1-independent pathways. In the current study, the protein levels of p-PI3K and AKT in the liver were increased by $0.40 \%$ Met, consistent with SREBP1 but not TOR, which might imply that low dietary Met level $(0.40 \%)$ increased hepatic lipid accumulation in a PI3K/AKT-SREBP1 independent TOR manner.

In contrast to the lipid synthesis promoted by $0.40 \%$ Met in the liver, high dietary Met level $(0.84 \%$ and $1.28 \%$ ) tended to promote lipogenesis in the muscle in this study. The evidence was that the relative expression levels of lipogenesis genes including SREBP1, ACC, and FAS, were markedly induced by $0.84 \%$ and $1.28 \%$ dietary Met in the muscle of blunt snout bream. The results were in line with turbot primary muscle cells treated with Met deprivation, which significantly reduced the relative mRNA expression of FAS and SREBP1 than those in the control group [13]. Latimer et al. [18] demonstrated similar results: 
rainbow trout fed Met restricted diets for 8 weeks showed increased fat accumulation in the liver and decreased fat accumulation in the muscle. Meanwhile, different with elevated PI3K/AKT in the liver induced by the $0.40 \%$ diet, the protein levels of p-PI3K and AKT in the muscle were both very low compared with those in the liver in the $0.40 \%$ and $0.84 \%$ Met dets. The results indicated that Met regulated lipogenesis was species-dependent in fish.

\section{Higher dietary methionine levels $(0.84 \%$ and $1.28 \%)$ induced fatty acid $\beta$-oxidation in both the liver and muscle of juvenileMegalobrama amblycephalathan $0.40 \%$ diet}

Unlike lipogenesis, $\beta$-oxidation is a process of fatty acid degradation, which supplies energy for the body. In the present study, higher dietary Met levels $(0.84 \%$ and $1.28 \%)$ induced fatty acid $\beta$-oxidation in both the liver and muscle of Megalobrama amblycephala, which was demonstrated by the expression levels of PPARa (except in muscle) and its downstream: CPT1 [47], were significantly upregulated by $0.84 \%$ and $1.28 \%$ Met compared with the $0.40 \%$ diet. Induced muscular PPARa mRNA levels were found in fish fed the $1.28 \%$ Met diet, higher than that in fish fed the $0.40 \%$ diet. Rolland et al. [16] reported the similar results in rainbow trout that hepatic CPT1 expression levels in the low Met group were lower than those in the high Met group. In juvenile tiger puffer (Takifugu rubripes), lipolytic gene (ACOX1 and HSL) expression levels were significantly induced by high dietary Met [48]. In the present study, $0.84 \%$ dietary Met increased hepatic lipase mRNA expression levels compared with the $1.28 \%$ diet, and could catalyze triglyceride [49]. High Met preferentially improved muscular lipolysis, as evidenced by the muscular LPL mRNA level being induced by $1.28 \%$ methionine in this study. The results of our present study implied that high dietary Met levels $(0.84 \%$ or $1.28 \%$ ) were more conductive to promoting lipolysis in the liver and muscle than the $0.40 \%$ dietary Met. These results also revealed the different lipolysis responses to dietary Met in the liver and muscle of juvenile blunt snout bream. The induced lipolysis and $\beta$-oxidation not only provide energy for the growth and Met of blunt snout bream, but also may partly contribute to the plasma TG and TC contents that did not show significant differences among the experimental groups. Similar results were shown in juvenile silver pompano, Trachinotus blochii (Lacepede, 1801) [50].

\section{Changes in glucose metabolism in the liver and muscle ofMegalobrama amblycephalain response to dietary methionine were dose dependent}

The liver, as the main tissue of glucose homeostasis, plays a key role in regulating intermediary metabolism in response to nutritional status $[51,52]$. In the present study, the highest expression levels of GLUT2 were found in the $1.28 \%$ Met diet, which promoted glucose transfer between blood and liver and glucose catabolism and might be helpful for stable plasma glucose content [53]. Hepatic GK, PFK and PK expression levels were significantly induced by dietary $0.84 \%$ Met level, suppressed by $1.28 \%$ dietary Met; while PFK and PK expression in the muscle were increased by the $1.28 \%$ diet compared with the control diet $(0.40 \%)$. The present data about glycolysis revealed that $0.84 \%$ dietary Met potentially promoted hepatic glucose utilization while muscular glucose utilization was enhanced by $1.28 \%$ dietary Met. Similar results were observed in cobia, in which $1.24 \%$ dietary Met enhanced hepatic glycolysis via increased PK mRNA levels compared with an $0.70 \%$ diet [14]. Primary muscle cells of turbot treated with 
Met deprivation exhibited decreased GK and PK expression levels compared with the control [13]. The energy released by enhanced glycolysis in both the liver and muscle may contribute to the growth of blunt snout bream. In addition, the increased muscular glycolysis in the $1.28 \%$ diet may provide a substrate for lipid synthesis as shown in this study [54]. Additionally, in the current study, $0.40 \%$ dietary Met significantly induced hepatic GK and PFK expression levels compared with 1.28\% Met level, while PK was not impacted. This result indicated that $0.40 \%$ Met potentially promoted the preparation stage of glycolysis, but did not promote entry into the energy release stage [54], which may be part of the reason that low dietary Met led to poor growth.

Regarding gluconeogenesis, another way of glucose metabolism, juvenile blunt snout bream fed $1.28 \%$ Met diet showed marked mRNA upregulation of the rate-limiting enzymes: PEPCK and G6Pase in the liver. In addition, the study was in accordance with Skiba-Cassy et al. [55], who found that feeding rainbow trout a high Met diet significantly enhanced the expression of hepatic G6Pase2 and PEPCK $2 \mathrm{~h}$ after a meal. And the results also in agreement with Dai et al. [36] and Lansard et al. [1], who reported that high levels of amino acid markedly up-regulated hepatic gluconeogenic gene mRNA levels in trout compared with those in fish treated with one-fold amino acid. Interestingly, combined with the hypothesis about glycolysis in muscle described above, Megalobrama amblycephala fed $1.28 \%$ diet may activate the Cori cycle between liver and muscle, which can effectively reuse lactic acid, and supply energy and glucose to other tissues [56]. In addition, dietary Met supplementation (0.84\% and $1.28 \%)$ significantly increased hepatic GS expression to promote hepatic glycogen synthesis. Higher dietary Met tended to enhance glucose and glycogen synthesis, which might be partly due to Met being a glucogenic amino acid [16]. In the muscle, $1.28 \%$ dietary Met markedly increased PEPCK mRNA levels in the current study to promote the production of phosphoenolpyruvate, which might help to activate PK and potentially link with lipid catabolism $[54,57,58]$.

\section{Conclusions}

In summary, this study revealed that optimal dietary Met could enhance growth performance and nutrient metabolism in blunt snout bream in response to dietary Met levels in a tissue-specific manner. The $0.40 \%$ dietary Met downregulated hepatic key TOR signaling genes, while improved muscular TOR signaling. The $0.40 \%$ Met diet increased hepatic lipid accumulation in a PI3K/AKT-SREBP1 independent TOR manner, while suppressed lipogenesis in muscle. Higher dietary Met levels $(0.84 \%$ and $1.28 \%)$ induced fatty acid $\beta$-oxidation in both the liver and muscle of blunt snout bream. Regarding glucose catabolism, the effect of dietary Met on catabolism in the liver and muscle of juvenile was dose-dependent (Fig. 5).

Unfortunately, as metabolism is a dynamic process, a limitation of this experiment is that it only evaluated metabolism at $24 \mathrm{~h}$ after feeding. It may be surprising to study the change that occur at multiple time points.

\section{Abbreviations}


4E-BP1, Eukaryotic initiation factor 4E binding protein-1; ACC, Acetyl-CoA carboxylase; AKT, Protein kinase B; CPT1, Carnitine palmitoyl transferase 1; FAS, Fatty acid synthetase; FBP, Fructose-1,6-biphosphatase; FBW, Final body weight; FCR, Feed conversion ratio; G6Pase, Glucose-6-phosphatase; G6PDH, Glucose-6phosphate dehydrogenase; GK, Glucokinas; GLU, Glucose; GLUT2, Glucose transporters 2; GLUT4, Glucose transporters 4; GS, Glycogen synthase; IBW, Initial body weight; LPL, Lipoprotein lipase; PEPCK, Phosphoenolpyruvate carboxykinase; PFK, Phosphofructokinase; PI3K, Phosphatidylinositol 3-kinase; PK, Pyruvate kinase; PPARa, Peroxisome proliferator activated receptor alpha; S6K1, Ribosomal protein S6 kinase 1; SGR, Specific growth rate; SREBP1, Sterol regulatory element-binding protein 1; TC, Total triglyceride; TG, Total cholesterol; TOR, Target of rapamycin; WGR, Weight gain rate.

\section{Declarations}

\section{Availability of data and materials}

The datasets produced and/or analyzed during the current study are available from the corresponding author on reasonable request.

\section{Ethics approval and consent to participate}

The protocols used on the experimental fish followed the guidelines of the Institutional Animal Care and Ethics Committee of Nanjing Agricultural University, Nanjing, China. [Permit number: SYXK (Su) 20110036].

\section{Competing interests}

The authors declare that they have no competing interests.

\section{Consent for publication}

Not applicable.

\section{Authors' contributions}

MCR designed the research. KJ conducted the trail, analyzed the data, and wrote the paper. HLL provided technical assistance and contributed to the preparation of the tables and figures. HY provided the assistance for chemical analysis and revised the manuscript. LZ and LKP provided their technical assistance for the feeding trail. XPG, MCR, and HLL supervised the design of the study and data analysis, and revised the manuscript. All authors read and approved the final manuscript.

\section{Authors' information}

KJ: E-mail, Jeki_Ji@163.com; phD student.

HLL: E-mail, hualiang_liang@163.com; research associate. 
MCR: E-mail, renmc@ffrc.cn; professor.

XPG: E-mail, gexp@ffrc.cn; professor.

LZ: E-mail, zhangl21@tongwei.com; phD.

LKP: E-mail, panlk@ffrc.cn; research associate.

HY: E-mail: 2500941964@qq.com; phD student.

\section{Author details}

${ }^{1}$ Wuxi Fisheries College, Nanjing Agricultural University, Wuxi 214081, China;

${ }^{2}$ Key Laboratory for Genetic Breeding of Aquatic Animals and Aquaculture Biology, Freshwater Fisheries Research Center (FFRC), Chinese Academy of Fishery Sciences (CAFS), Wuxi 214081, China.

${ }^{3}$ Tongwei Co., Ltd., Chengdu 610093; Healthy Aquaculture Key Laboratory of Sichuan Province, China.

\section{Acknowledgments}

Not applicable.

\section{Funding}

This study was financially supported by the National Key Research and Development Program of China (2018YFD0900400), the Natural Science Foundation of Jiangsu Province (BK20200169), the Modern Agriculture Industrial Technology System special project the National Technology System for Conventional Freshwater Fish Industries (CARS-45).

\section{References}

1. Lansard M, Panserat S, Plagnes-Juan E, Dias K, Seiliez I, Skiba-Cassy S. L-Leucine, L-Methionine, and L-Lysine Are Involved in the Regulation of Intermediary Metabolism-Related Gene Expression in Rainbow Trout Hepatocytes. The Journal of Nutrition. 2010; doi:10.3945/jn.110.124511.

2. Martínez Y, Li X, Liu G, Bin P, Yan WX, Más D, et al. The role of methionine on metabolism, oxidative stress, and diseases. Amino Acids. 2017; doi:10.1007/s00726-017-2494-2.

3. Blachier F, Wu G, Yin Y. Nutritional and Physiological Functions of Amino Acids in Pigs. Springer Vienna; 2013.

4. Castellano R, Perruchot MH, Conde-Aguilera JA, van Milgen J, Collin A, Tesseraud S, et al. A Methionine Deficient Diet Enhances Adipose Tissue Lipid Metabolism and Alters Anti-Oxidant Pathways in Young Growing Pigs. PLOS ONE. 2015; doi:10.1371/journal.pone.0130514. 
5. Mai KS, Wan JL, Ai QH, Xu W, Liufu ZG, Zhang L, et al. Dietary methionine requirement of large yellow croaker, Pseudosciaena crocea R. Aquaculture. 2006; doi:10.1016/j.aquaculture.2005.08.010.

6. Wang ZX, Liang MC, Li H, Cai L, He HJ, Wu Q, Yang L. I-Methionine activates Nrf2-ARE pathway to induce endogenous antioxidant activity for depressing ROS-derived oxidative stress in growing rats. Journal of the Science of Food and Agriculture. 2019; doi:10.1002/jsfa.9757.

7. Wu P, Tang L, Jiang WD, Hu K, Liu Y, Jiang J, et al. The relationship between dietary methionine and growth, digestion, absorption, and antioxidant status in intestinal and hepatopancreatic tissues of sub-adult grass carp (Ctenopharyngodon idella). Journal of Animal Science and Biotechnology. 2017; doi:10.1186/s40104-017-0194-0.

8. Conde-Aguilera JA, Barea R, Le Floc'h N, Lefaucheur L, van Milgen J. A sulfur amino acid deficiency changes the amino acid composition of body protein in piglets. Animal. 2010; doi:10.1017/s1751731110000340.

9. Zeitz JO, Mohrmann S, Käding SC, Devlikamov M, Niewalda I, Whelan R, et al. Effects of methionine on muscle protein synthesis and degradation pathways in broilers. Journal of Animal Physiology and Animal Nutrition.2018; doi:10.1111/jpn.13026.

10. Perrone CE, Mattocks DA, Plummer JD, Chittur SV, Mohney R, Vignola K, et al. Genomic and metabolic responses to methionine-restricted and methionine-restricted, cysteine-supplemented diets in Fischer 344 rat inguinal adipose tissue, liver and quadriceps muscle. Nutrigenetics and Nutrigenomics. 2012; doi:10.1159/000339347.

11. Plaisance EP, Greenway FL, Boudreau A, Hill KL, Johnson WD, Krajcik RA, et al. Dietary methionine restriction increases fat oxidation in obese adults with metabolic syndrome. The Journal of Clinical Endocrinology \& Metabolism. 2011; doi:10.1210/jc.2010-2493.

12. Yin J, Ren WK, Chen S, Li YY, Han H, Gao J, et al. Metabolic Regulation of Methionine Restriction in Diabetes. Molecular Nutrition \& Food Research.2018; doi:10.1002/mnfr.201700951.

13. Jiang HW, Bian FY, Zhou HH, Wang X, Wang KD, Mai KS, et al. Nutrient sensing and metabolic changes after methionine deprivation in primary muscle cells of turbot (Scophthalmus maximus). Journal of Nutritional Biochemistry. 2017; doi:10.1016/j.jnutbio.2017.08.015.

14. Chi SY, He YF, Zhu Y, Tan BP, Dong XH, Yang QH, et al. Dietary methionine affects growth and the expression of key genes involved in hepatic lipogenesis and glucose metabolism in cobia (Rachycentron canadum). Aquaculture Nutrition. 2019; doi:10.1111/anu.13006.

15. Wang Z, Mai KS, Xu W, Zhang YJ, Liu YL, Ai QH. Dietary methionine level influences growth and lipid metabolism via GCN2 pathway in cobia (Rachycentron canadum). Aquaculture. 2016; doi:10.1016/j.aquaculture.2015.12.019.

16. Rolland M, Skov PV, Larsen BK, Holm J, Gómez-Requeni P, Dalsgaard J. Increasing levels of dietary crystalline methionine affect plasma methionine profiles, ammonia excretion, and the expression of genes related to the hepatic intermediary metabolism in rainbow trout (Oncorhynchus mykiss). Comparative Biochemistry and Physiology Part B: Biochemistry and Molecular Biology. 2016; doi:10.1016/j.cbpb.2016.04.006. 
17. Song YF, Gao Y, Hogstrand C, Li DD, Pan YX, Luo Z. Upstream regulators of apoptosis mediates methionine-induced changes of lipid metabolism. Cellular Signalling. 2018; doi:10.1016/j.cellsig.2018.08.005.

18. Latimer MN, Cleveland BM, Biga PR. Dietary methionine restriction: Effects on glucose tolerance, lipid content and micro-RNA composition in the muscle of rainbow trout. Comparative Biochemistry and Physiology Part C: Toxicology \& Pharmacology. 2018; doi:10.1016/j.cbpc.2017.10.012.

19. Craig PM, Moon TW. Methionine restriction affects the phenotypic and transcriptional response of rainbow trout (Oncorhynchus mykiss) to carbohydrate-enriched diets. British Journal of Nutrition. 2012; doi:10.1017/s0007114512001663

20. Sheridan MA. Lipid dynamics in fish: aspects of absorption, transportation, deposition and mobilization. Comparative Biochemistry and Physiology Part B: Comparative Biochemistry. 1988; doi:10.1016/0305-0491(88)90322-7.

21. Seiliez I, Gabillard JC, Skiba-Cassy S, Garcia-Serrana D, Gutiérrez J, Kaushik S, et al. An in vivo and in vitro assessment of TOR signaling cascade in rainbow trout (Oncorhynchus mykiss). American Journal of Physiology-Regulatory, Integrative and Comparative Physiology. 2008; doi:10.1152/ajpregu.00146.2008.

22. Tu YQ, Xie SQ, Han D, Yang YX, Jin JY, Zhu XM. Dietary arginine requirement for gibel carp (Carassis auratus gibelio CAS III) reduces with fish size from $50 \mathrm{~g}$ to $150 \mathrm{~g}$ associated with modulation of genes involved in TOR signaling pathway. Aquaculture. 2015; doi:10.1016/j.aquaculture.2015.02.031.

23. Wacyk J, Powell M, Rodnick K, Overturf K, Hill RA, Hardy R. Dietary protein source significantly alters growth performance, plasma variables and hepatic gene expression in rainbow trout (Oncorhynchus mykiss) fed amino acid balanced diets. Aquaculture. 2012; doi:10.1016/j.aquaculture.2012.05.013.

24. Xu DD, He G, Mai KS, Zhou HH, Xu W, Song F. Postprandial nutrient-sensing and metabolic responses after partial dietary fishmeal replacement by soyabean meal in turbot (Scophthalmus maximus). British Journal of Nutrition. 2015; doi:10.1017/s0007114515004535.

25. Chen QL, Gong Y, Luo Z, Zheng JL, Zhu QL. Differential effect of waterborne cadmium exposure on lipid metabolism in liver and muscle of yellow catfish Pelteobagrus fulvidraco. Aquatic Toxicology. 2013; doi:10.1016/j.aquatox.2013.09.011.

26. Seiliez I, Panserat S, Lansard M, Polakof S, Plagnes-Juan E, Surget A, et al. Dietary carbohydrate-toprotein ratio affects TOR signaling and metabolism-related gene expression in the liver and muscle of rainbow trout after a single meal. American Journal of Physiology-Regulatory, Integrative and Comparative Physiology. 2011; doi:10.1152/ajpregu.00579.2010.

27. Liao YJ, Ren MC, Liu B, Sun SM, Cui HH, Xie J, et al. Dietary methionine requirement of juvenile blunt snout bream (Megalobrama amblycephala) at a constant dietary cystine level. Aquaculture Nutrition. 2014; doi:10.1111/anu.12131.

28. Ji K, Liang HL, Ren MC, Ge XP, Mi HF, Pan LK, et al. The immunoreaction and antioxidant capacity of juvenile blunt snout bream (Megalobrama amblycephala) involves the PI3K/Akt/Nrf2 and NF-KB 
signal pathways in response to dietary methionine levels. Fish \& Shellfish Immunology. 2020; doi:10.1016/j.fsi.2020.07.005.

29. Official methods of analysis of the association of official analytical chemists. 15th ed. Arlington, VA: Association of Official Analytical Chemists Inc; 2003.

30. Gao ZX, Luo W, Liu H, Zeng C, Liu XL, Yi SK, et al. Transcriptome Analysis and SSR/SNP Markers Information of the Blunt Snout Bream (Megalobrama amblycephala). PLoS ONE. 2012; doi:10.1371/journal.pone.0042637.

31. Chu ZJ, Gong Y, Lin YC, Yuan YC, Cai WJ, Gong SY, et al. Optimal dietary methionine requirement of juvenile Chinese sucker, Myxocyprinus asiaticus. Aquaculture Nutrition. 2014; doi:10.1111/anu.12071.

32. Zhou QC, Wu ZH, Tan BP, Chi SY, Yang QH. Optimal dietary methionine requirement for Juvenile Cobia (Rachycentron canadum). Aquaculture. 2006; doi:10.1016/j.aquaculture.2006.03.035.

33. Ahmed I, Khan MA, Jafri AK. Dietary methionine requirement of fingerling Indian major carp, Cirrhinus mrigala (Hamilton). Aquaculture International. 2003; doi:10.1023/b:aqui.0000004181.89420.a2.

34. Yan Q, Xie S, Zhu X, Lei W, Yang Y. Dietary methionine requirement for juvenile rockfish, Sebastes schlegeli. Aquaculture Nutrition. 2007; doi:10.1111/j.1365-2095.2007.00461.x.

35. Hay N. Upstream and downstream of mTOR. Genes \& Development. 2004; doi:10.1101/gad.1212704.

36. Dai W, Panserat S, Plagnes-Juan E, Seiliez I, Skiba-Cassy S. Amino acids attenuate insulin action on gluconeogenesis and promote fatty acid biosynthesis via mTORC1 signaling pathway in trout hepatocytes. Cellular Physiology and Biochemistry. 2015; doi:10.1159/000430281.

37. Zhang YL, Wang P, Lin S, Mercier Y, Yin HJ, Song YM, et al. mTORC1 signaling-associated protein synthesis in porcine mammary glands was regulated by the local available methionine depending on methionine sources. Amino Acids. 2017; doi:10.1007/s00726-017-2496-0.

38. Bauman DE, Harvatine KJ, Lock AL. Nutrigenomics, rumen-derived bioactive fatty acids, and the regulation of milk fat synthesis. Annual Review of Nutrition. 2011; doi:

1146/annurev.nutr.012809.104648.

39. Porstmann T, Santos CR, Griffiths B, Cully M, Wu M, Leevers S, et al. SREBP activity is regulated by mTORC1 and contributes to Akt-dependent cell growth. Cell Metabolism. 2008; doi:10.1016/j.cmet.2008.07.007.

40. Espe M, Rathore RM, Du ZY, Liaset B, El-Mowafi A. Methionine limitation results in increased hepatic FAS activity, higher liver 18:1 to 18:0 fatty acid ratio and hepatic TAG accumulation in Atlantic salmon, Salmo salar. Amino Acids. 2010; doi:10.1007/s00726-009-0461-2.

41. Seiliez I, Vélez EJ, Lutfi E, Dias K, Plagnes-Juan E, Marandel L, et al. Eating for two: consequences of parental methionine nutrition on offspring metabolism in rainbow trout (Oncorhynchus mykiss). Aquaculture. 2017; doi:10.1016/j.aquaculture.2017.01.010.

42. Krycer JR, Sharpe LJ, Luu W, Brown AJ. The Akt-SREBP nexus: cell signaling meets lipid metabolism. Trends in Endocrinology \& Metabolism. 2010; doi:10.1016/j.tem.2010.01.001. 
43. Smith TM, Gilliland K, Clawson GA, Thiboutot D. IGF-1 induces SREBP-1 expression and lipogenesis in SEB-1 sebocytes via activation of the phosphoinositide 3-Kinase/Akt pathway. Journal of Investigative Dermatology. 2008; doi:10.1038/sj.jid.5701155.

44. Leavens KF, Easton RM, Shulman GI, Previs SF, Birnbaum MJ. Akt2 is required for hepatic lipid accumulation in models of insulin resistance. Cell Metabolism. 2009; doi:10.1016/j.cmet.2009.10.004.

45. Ono H, Shimano H, Katagiri H, Yahagi N, Sakoda H, Onishi Y, et al. Hepatic Akt activation induces marked hypoglycemia, hepatomegaly, and hypertriglyceridemia with sterol regulatory element binding protein involvement. Diabetes. 2003; doi:10.2337/diabetes.52.12.2905.

46. Yecies JL, Zhang HH, Menon S, Liu S, Yecies D, Lipovsky Al, et al. Akt stimulates hepatic SREBP1c and lipogenesis through parallel mTORC1-dependent and independent pathways. Cell Metabolism. 2011; doi:10.1016/j.cmet.2011.06.002.

47. Kerner J, Hoppel C. Fatty acid import into mitochondria. Biochimica et Biophysica Acta (BBA) Molecular and Cell Biology of Lipids. 2000; doi:10.1016/s1388-1981(00)00044-5.

48. Xu HG, Zhang QG, Wei YL, Liao ZB, Liang MQ. Dietary methionine increased the lipid accumulation in juvenile tiger puffer Takifugu rubripes. Comparative Biochemistry and Physiology Part B:

Biochemistry and Molecular Biology. 2019; doi:10.1016/j.cbpb.2019.01.005.

49. Sharma R, Chisti Y, \& Banerjee UC. Production, purification, characterization, and applications of lipases. Biotechnology Advances. 2001; doi:10.1016/S0734-9750(01)00086-6.

50. Ebeneezar S, Vijayagopal P, Srivastava PP, Gupta S, Varghese T, Prabu D L, et al. Optimum dietary methionine requirement of juvenile silver pompano, Trachinotus blochii (Lacepede, 1801). Animal Feed Science and Technology. 2020; doi:10.1016/j.anifeedsci.2020.114592

51. Klover PJ, Mooney RA. Hepatocytes: critical for glucose homeostasis. International Journal of Biochemistry \& Cell Biology. 2004; doi: 1016/j.biocel.2003.10.002.

52. Pilkis SJ, Granner DK. Molecular physiology of the regulation of hepatic gluconeogenesis and glycolysis. Annual Review of Physiology. 1992; doi:10.1146/annurev.ph.54.030192.004321.

53. Granner D, Pilkis S. The genes of hepatic glucose metabolism. Journal of Biological Chemistry. 1990; doi:10.1016/0005-2728(90)90194-9.

54. Wang JY, Zhu CG, Xu CF. Biochemistry. 3th ed. Beijing, China, Higher Education Press; 2007.

55. Skiba-Cassy S, Geurden I, Panserat S, Seiliez I. Dietary methionine imbalance alters the transcriptional regulation of genes involved in glucose, lipid and amino acid metabolism in the liver of rainbow trout (Oncorhynchus mykiss). Aquaculture. 2016; doi:10.1016/j.aquaculture.2015.12.015.

56. Gooch JW. Cori Cycle. Springer New York; 2011.

57. Hakimi P, Yang J, Casadesus G, Massillon D, Tolentino-Silva F, Nye CK, et al. Overexpression of the cytosolic form of phosphoenolpyruvate carboxykinase (GTP) in skeletal muscle repatterns energy metabolism in the mouse. Journal of Biological Chemistry. 2007; doi:10.1074/jbc.m706127200. 
58. Ren ZJ, Wang Y, Ren YY, Zhang ZW, Gu WW, Wu ZT, et al. Enhancement of porcine intramuscular fat content by overexpression of the cytosolic form of phosphoenolpyruvate carboxykinase in skeletal muscle. Scientific Reports. 2017; doi:10.1038/srep43746.

\section{Figures}

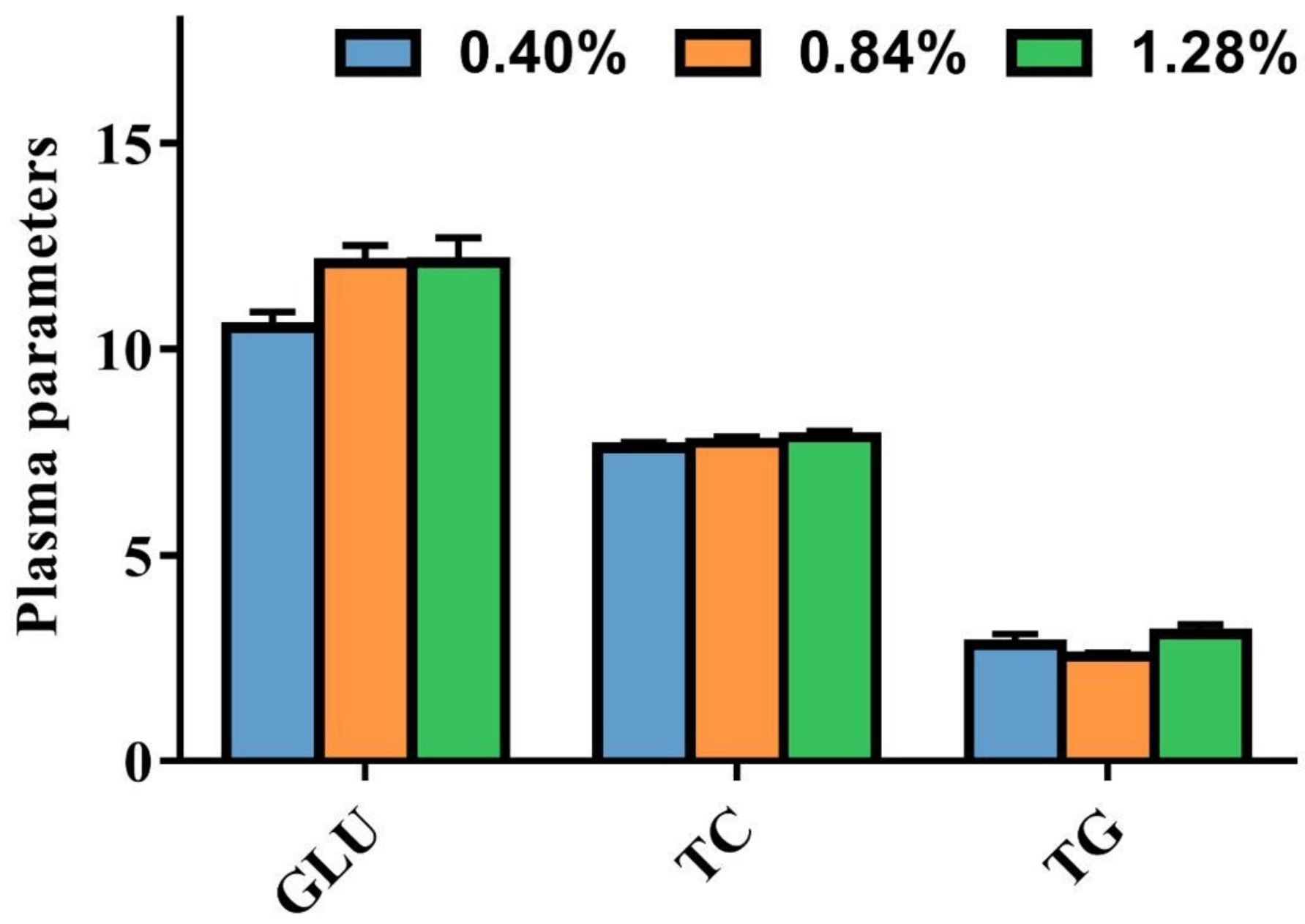

Figure 1

The plasma parameters in Megalobrama amblycephala fed grade methionine diets. Data are expressed as means with SEM $(n=8)$. Values with different letters in lower case are significantly different $(P<0.05)$. GLU, Glucose; TC, Total triglyceride; TG, Total cholesterol. 
A

$\begin{array}{llll}\text { L1 } & \text { L2 } & \text { M1 } & \text { M2 }\end{array}$
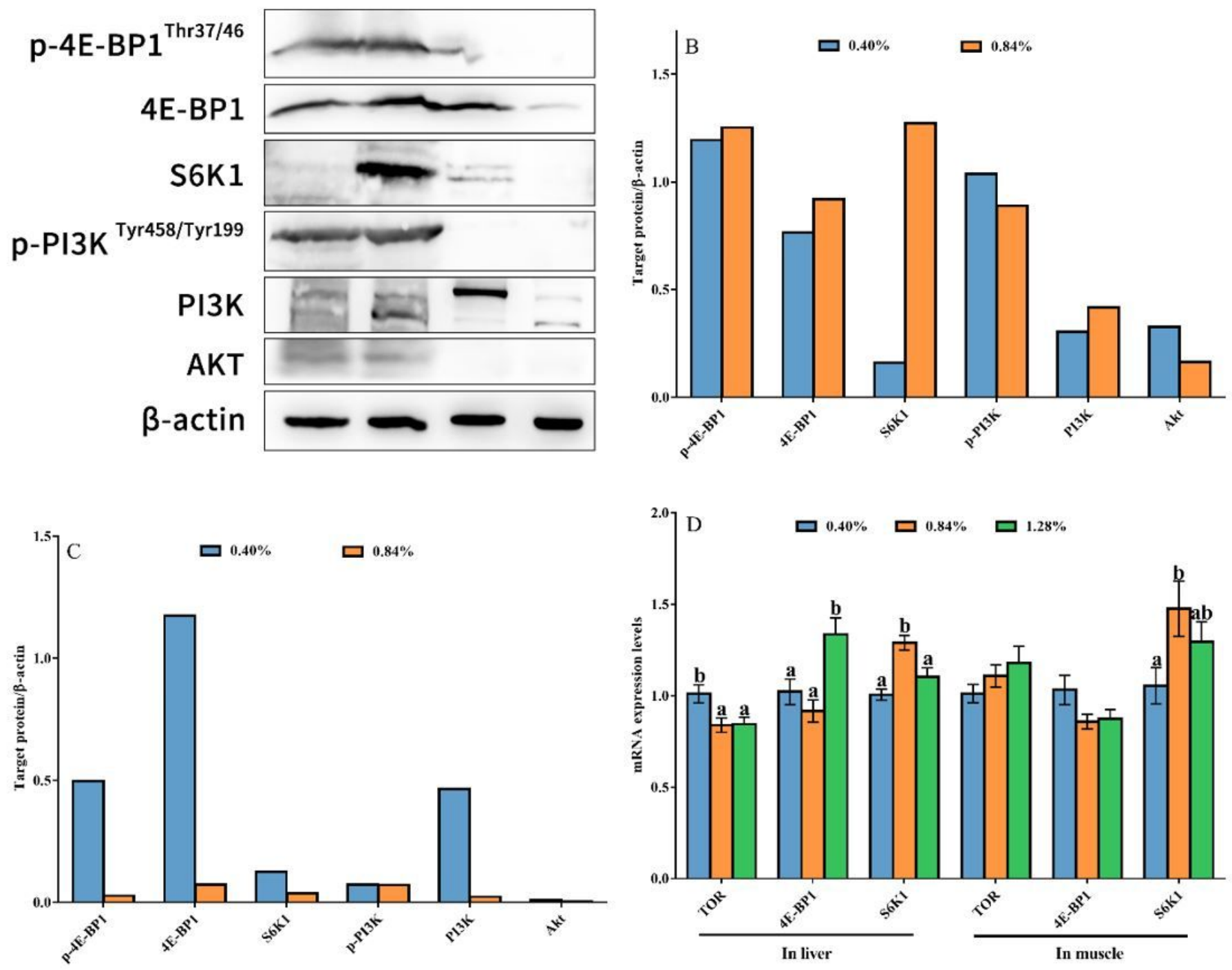

Figure 2

TOR and PI3K signaling in liver and muscle of Megalobrama amblycephala fed grade methionine diets. The protein levels and/or phosphorylation of 4E-BP1, S6K1, PI3K and AKT were examined by western blots (A) and quantitated in liver (B) and muscle (C). mRNA levels of TOR signaling were quantified in liver and muscle (D). Data are expressed as means with SEM. Values with different letters in lower case are significantly different $(P<0.05)$. L1, L2 means liver in $0.40 \%$ and $0.84 \%$ respectively; $M 1, M 2$ means muscle in $0.40 \%$ and $0.84 \%$ respectively. TOR, Target of rapamycin; $4 \mathrm{E}-\mathrm{BP} 1$, Eukaryotic initiation factor $4 \mathrm{E}$ binding protein-1; S6K1, Ribosomal protein S6 kinase 1; PI3K, Phosphatidylinositol 3-kinase; AKT, Protein kinase B. 

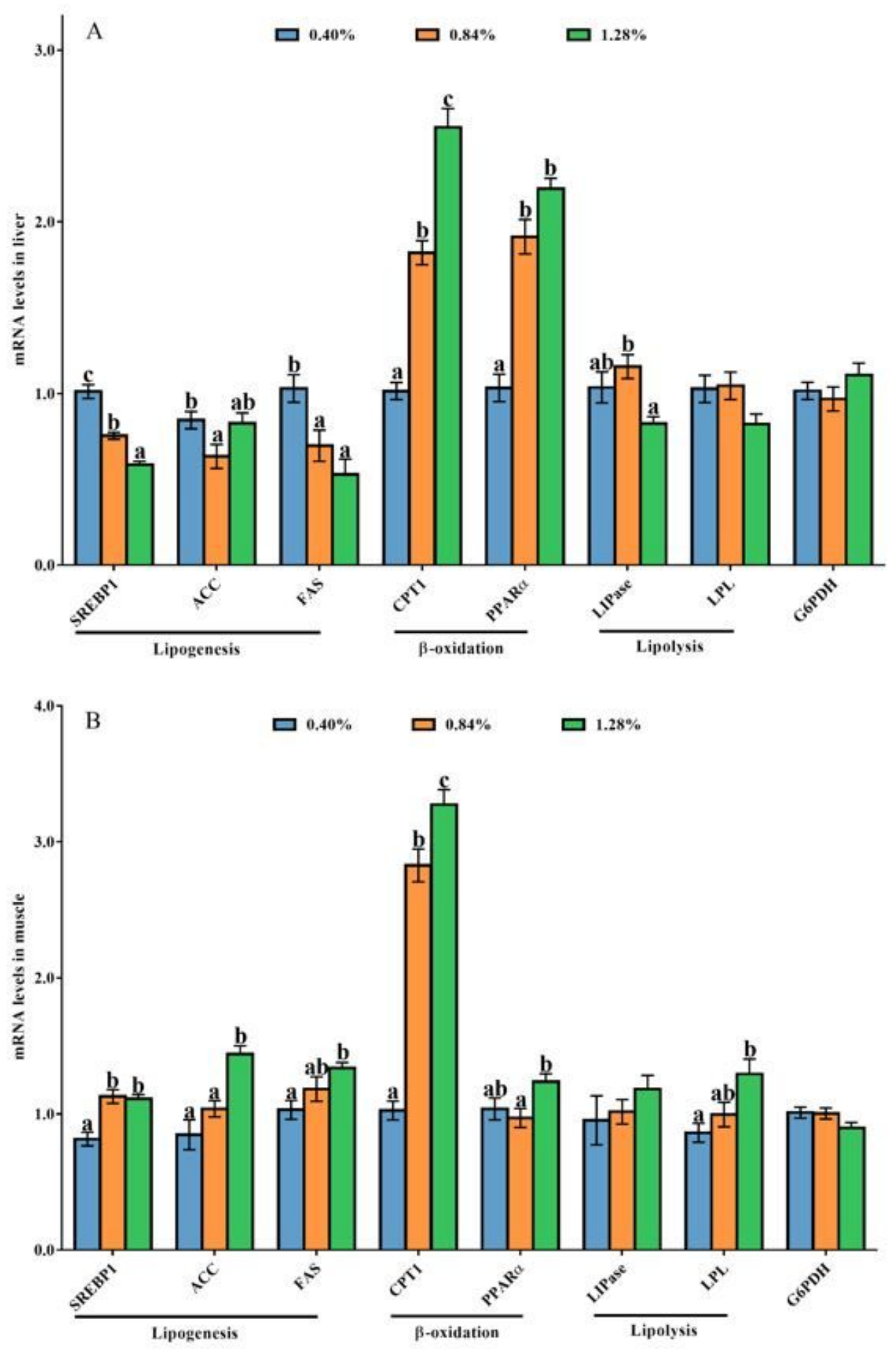

Figure 3

Lipometabolism gene mRNA levels in liver and muscle of Megalobrama amblycephala fed graded methionine diets. A: liver, B: muscle. Data are expressed as means with SEM $(n=12)$. Values with different letters in lower case are significantly different $(P<0.05)$. SREBP1, Sterol regulatory element-binding protein 1; ACC, Acetyl-CoA carboxylase; FAS, Fatty acid synthetase; CPT1, Carnitine palmitoyl transferase 
1; PPARa, Peroxisome proliferator activated receptor alpha; LPL, Lipoprotein lipase; G6PDH, Glucose-6phosphate dehydrogenase.
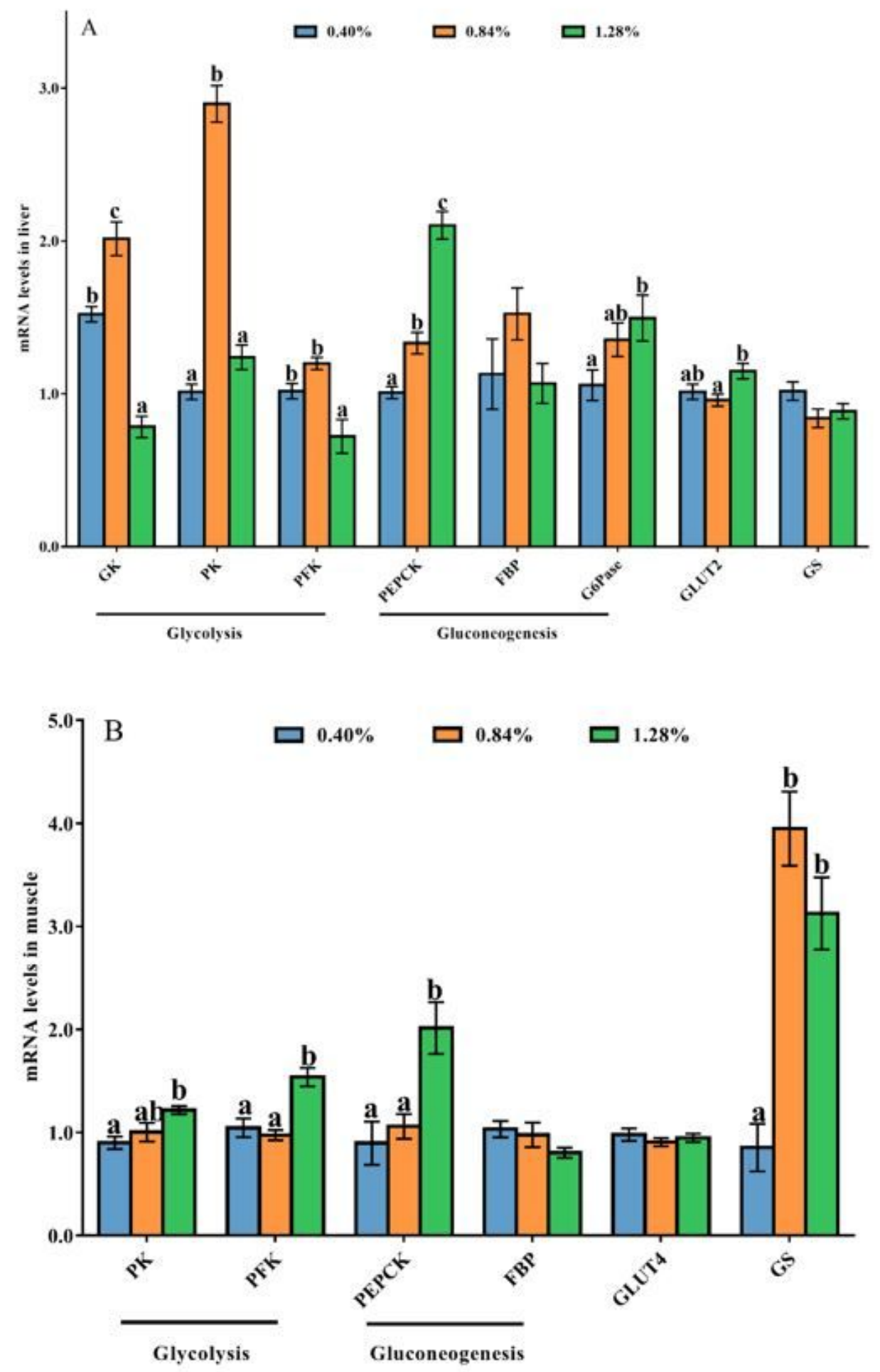

Figure 4

Glycometabolism gene mRNA levels in liver and muscle of Megalobrama amblycephala fed graded methionine diets. A: liver, B: muscle. Data are expressed as means with SEM $(n=12)$. Values with different letters in lower case are significantly different $(P<0.05)$. GK, Glucokinase; PK, Pyruvate kinase; PFK, 
Phosphofructokinase; PEPCK, Phosphoenolpyruvate carboxykinase; FBP, Fructose-1,6-biphosphatase; G6Pase, Glucose-6-phosphatase; GLUT2, Glucose transporters 2; GLUT4, Glucose transporters 4; GS, Glycogen synthase.

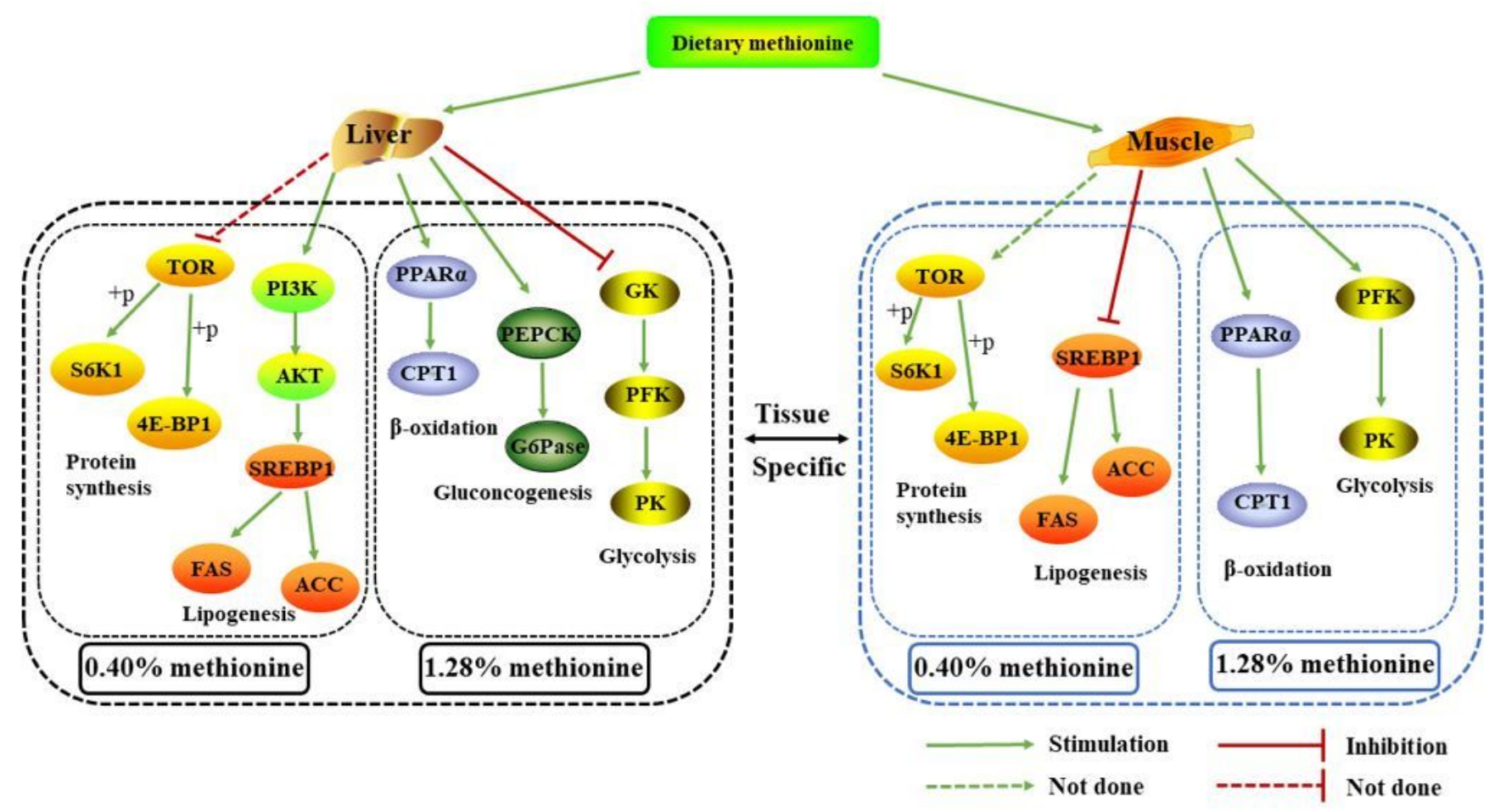

\section{Figure 5}

Scheme summarizing the nutrient metabolism in response to dietary methionine levels in juvenile Megalobrama amblycephala. TOR, Target of rapamycin; 4E-BP1, Eukaryotic initiation factor 4E binding protein-1; S6K1, Ribosomal protein S6 kinase 1; PI3K, Phosphatidylinositol 3-kinase; AKT, Protein kinase B; SREBP1, Sterol regulatory element-binding protein 1; ACC, Acetyl-CoA carboxylase; FAS, Fatty acid synthetase; CPT1, Carnitine palmitoyl transferase 1; PPARa, Peroxisome proliferator activated receptor alpha; GK, Glucokinase; PK, Pyruvate kinase; PFK, Phosphofructokinase; PEPCK, Phosphoenolpyruvate carboxykinase; G6Pase, Glucose-6-phosphatase. 